\title{
Timing of rebleeding in high-risk peptic ulcer bleeding after successful hemostasis: A systematic review
}

\author{
Sara El Ouali MD ${ }^{1}$, Alan N Barkun MD MSc ${ }^{1,2}$, Myriam Martel BSc $^{1}$, Davide Maggio MD ${ }^{1}$
}

\begin{abstract}
S El Ouali, AN Barkun, M Martel, D Maggio. Timing of rebleeding in high-risk peptic ulcer bleeding after successful hemostasis: A systematic review. Can J Gastroenterol Hepatol 2014;28(10):543-548.
\end{abstract}

BACKGROUND: Peptic ulcer rebleeding (PUR) usually occurs within three days following endoscopic hemostasis. However, recent data have increasingly suggested delayed rebleeding.

OBJECTIVE: To better characterize the timing of PUR (Forrest Ia to IIb) following initially successful endoscopic hemostasis.

METHODS: An exhaustive literature search (1989 to 2013), with cross-referencing, was performed to identify pertinent randomized controlled trial (RCT) arms. Patients receiving high-dose proton pump inhibitor (PPI) infusion following successful modern-day endoscopic hemostasis were included. A sensitivity analysis included any patients receiving PPI doses $>40 \mathrm{mg}$ daily. The main outcome measure was 30 -day rebleeding, while weighted mean averages at $\mathrm{t}=$ three, seven, 14 and 28 to 30 days are also reported.

RESULTS: Of 756 citations, six RCTs were included (561 patients; $58.5 \%$ to $89.5 \%$ male; 55.3 to 67.5 years of age). Among patients receiving high-dose PPI (five RCTs [393 patients]), 11.5\% (95\% CI $8.4 \%$ to $14.7 \%$ ) experienced rebleeding, $55.6 \%$ (95\% CI $41.1 \%$ to $70.1 \%$ ) rebled within three days, $20 \%$ (95\% CI $8.3 \%$ to $31.7 \%$ ) between four and seven days, $17.8 \%$ (95\% CI 6.6\% to 28.9\%) at eight to 14 days, and $6.7 \%$ ( $95 \%$ CI $0 \%$ to $14 \%$ ) at 15 to 28 to 30 days. Using the relaxed lower PPI dosing threshold, similar respective rates were $14.4 \%$ (95\% CI $11.5 \%$ to $17.3 \%$ ) overall, with interval rates of $39.5 \%$ (95\% CI $28.9 \%$ to $50.15 \%$ ), $34.6 \%$ (95\% CI $24.2 \%$ to $44.9 \%$ ), $19.7 \%$ (95\% CI $11 \%$ to $28.4 \%$ ) and $6.2 \%$ (95\% CI $0.95 \%$ to $11.5 \%$ ). Qualitative review of patient characteristics, limited by small sample size, possible bias and study heterogeneity, suggested increased patient comorbidity and postendoscopic use of lower PPI dosing may predict delayed rebleeding.

CONCLUSION: In patients with high-risk PUR undergoing successful endoscopic hemostasis, most rebled within three days, with many experiencing later rebleeding. Additional research is needed to better predict such an outcome.

Key Words: Endoscopic therapy; High-risk stigmata; Peptic ulcer bleeding; Rebleeding; Timing

\author{
Le moment de la reprise du saignement d'un ulcère \\ gastroduodénal à haut risque après une hémostase \\ réussie : une analyse systématique
}

HISTORIQUE : La reprise du saignement d'un ulcère gastroduodénal (RSUG) se produit généralement dans les trois jours suivant l'hémostase endoscopique. Cependant, des données récentes indiquent de plus en plus une reprise tardive du saignement.

OBJECTIF : Mieux caractériser le moment de la RSUG (Forrest Ia à IIb) après une hémostase endoscopique d'abord réussie.

MÉTHODOLOGIE : Les chercheurs ont procédé à une analyse bibliographique complète (de 1989 à 2013) avec référencement pour extraire les essais aléatoires et contrôlés pertinents (EAC). Étaient inclus les patients qui recevaient une infusion d'inhibiteur de la pompe à protons (IPP) à forte dose après une hémostase endoscopique moderne réussie. L'analyse de sensibilité incluait tous les patients ayant reçu une dose quotidienne d'IPP supérieure à $40 \mathrm{mg}$. La principale mesure d'issue était une reprise du saignement dans les 30 jours, tandis que les moyennes pondérées à $t=$ trois, sept, 14 et 28 à 30 jours étaient également précisées.

RÉSULTATS : Six EAC faisaient partie des 756 articles (561 patients; $58,5 \%$ à $89,5 \%$ d'hommes; 55,3 à 67,5 ans). Chez les patients qui avaient reçu un IPP à forte dose (cinq EAC [393 patients]), 11,5\% (95 \% IC 8,4\% à $14,7 \%$ ) ont subi une reprise des saignements, 55,6\% (95 \% IC 41,1\% à $70,1 \%)$ se sont remis à saigner dans les trois jours, $20 \%$ (95 \% IC 8,3 \% à $31,7 \%)$ au bout de quatre à sept jours, $17,8 \%$ (95 \% IC 6,6 \% à 28,9\%) au bout de huit à 14 jours, et 6,7\% (95\% IC $0 \%$ à $14 \%)$ au bout de 15 à entre 28 et 30 jours. Selon un seuil posologique rabaissé d'IPP, les taux similaires respectifs étaient de $14,4 \%$ (95\% IC 11,5\% à 17,3\%) dans l'ensemble, selon des taux d'intervalle de 39,5\% (95\% IC 28,9\% à 50,15\%), $34,6 \%$ (95 \% IC 24,2 \% à 44,9\%), 19,7\% (95 \% IC $11 \%$ à 28,4 \%) et 6,2 \% (95\% IC 0,95\% à 11,5\%). Une analyse qualitative des caractéristiques des patients, limitée par la petite taille de l'échantillon, les biais possibles et l'hétérogénéité des études, a laissé supposer qu'une comorbodité accrue des patients et une utilisation postendoscopique de posologies d'IPP plus faibles peuvent être prédictives d'une reprise tardive du saignement.

CONCLUSION : La plupart des patients très vulnérables à une RSUG qui subissent une hémostase endoscopique réussie se remettent à saigner dans les trois jours, et bon nombre présentent une reprise tardive du saignement. D'autres recherches s'imposent pour mieux prédire un tel résultat.

\footnotetext{
$\Delta$ cute upper gastrointestinal bleeding accounts for $>400,000$ hospiAtalizations per year in the United States, with the majority of cases being nonvariceal in origin. Peptic ulcer bleeding accounts for most cases of nonvariceal upper gastrointestinal bleeding and is a major cause of morbidity and mortality $(1,2)$. Recent advances in endoscopic hemostatic techniques and the use of high-dose intravenous (IV) proton pump inhibitors (PPIs) have been shown to improve outcomes in peptic ulcer bleeding (3). However, approximately $11 \%$ to $16 \%$ of patients with ulcers with high-risk stigmata (Forrest Ia to IIb) rebleed after initial endoscopic hemostasis, with most rebleeding reported to occur in the first $72 \mathrm{~h}(4-6)$.
}

The finding that most rebleeding occurs within the first three days is supported by several studies in which endoscopic follow-up of Forrest Ia to IIb ulcers showed healing with a clean base by day 3 to 4 (7-11); however, most of these older studies excluded patients with comorbidities, or patients on anticoagulants or nonsteroidal antiinflammatory drugs (NSAIDs), which is not reflective of a contemporary patient population $(7,9,11)$. In addition to these landmark studies, most of the current data on peptic ulcer rebleeding are derived from trials using endoscopic hemostatic techniques or pharmacological therapies that are not consistent with current recommendations, with use of epinephrine injection alone, low PPI doses or

Divisions of ${ }^{1}$ Gastroenterology and ${ }^{2}$ Clinical Epidemiology, McGill University, Montreal, Quebec

Correspondence: Dr Alan N Barkun, Division of Gastroenterology, The McGill University Health Centre, Montreal General Hospital site, 1650 Cedar

Avenue, Room D7-346, Montreal, Quebec H3G 1A4. Telephone 514-934-8309, e-mail alan.barkun@muhc.mcgill.ca

Received for publication June 17, 2014. Accepted September 8, 2014 


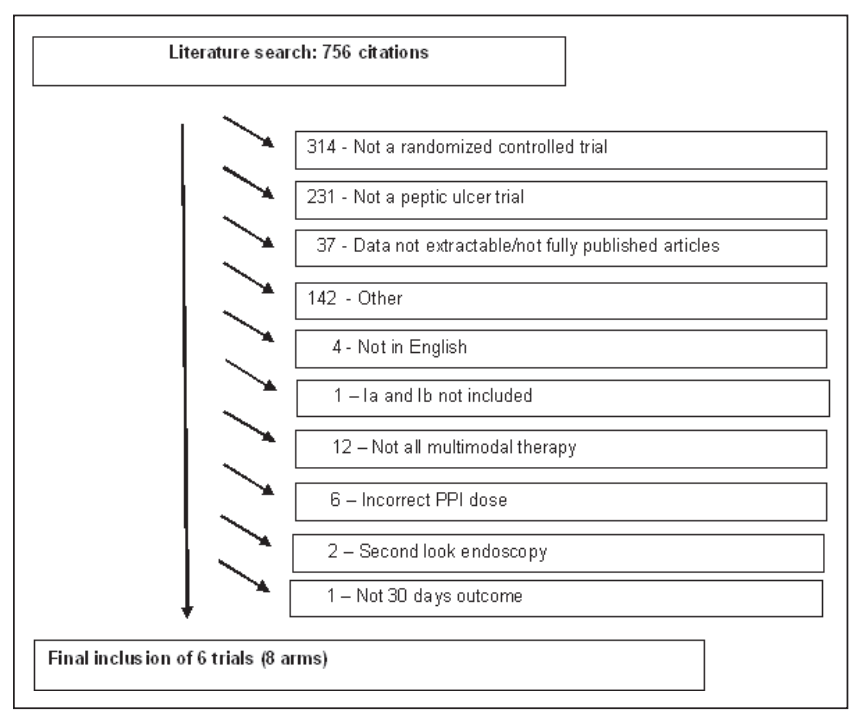

Figure 1) STROBE (STrengthening the Reporting of OBservational studies in Epidemiology) diagram. PPI Proton pump inhibitor

no PPI pharmacotherapy. In fact, more recent data from randomized trials suggest higher rates of rebleeding after three days (12-18).

The timing of rebleeding in the era of high-dose PPI and modernday endoscopic therapy thus remains unclear. In the context of increasing health care costs and pressure to discharge patients sooner, with many centres not tightly adhering to guidelines $(19,20)$, it is particularly important to clarify the timing of rebleeding.

The aim of the present systematic review was, accordingly, to examine the timing of peptic ulcer rebleeding in patients who exhibited high-risk stigmata having received recommended contemporary endoscopic and pharmacological therapies.

\section{METHODS}

\section{Search strategy}

A comprehensive computerized medical literature search was performed using the MEDLINE, EMBASE, Cochrane library and ISI Web of Knowledge databases from 1989 to September 2013. A highly sensitive search strategy was used to identify randomized controlled trials with a combination of controlled vocabulary and text words related to "upper gastrointestinal bleeding", "endoscopic therapy" and "PPIs". In addition, recursive searches and cross-referencing were performed; manual searches of articles identified after the initial search were also conducted.

\section{Study selection}

All human, adult studies published in French or English were considered. All randomized controlled trials were included if the study population fulfilled the following criteria: patients with peptic ulcer bleeding exhibiting high-risk stigmata (Forrest Ia to IIb); patients in whom successful initial hemostasis was achieved using contemporary endoscopic hemostatic methods (excluding epinephrine monotherapy), followed by PPIs at a dose $>40 \mathrm{mg}$ once daily. In addition, recorded outcomes needed to include rebleeding at different time points, up to 30 days. Any treatment arms of any of the studies not fulfilling these criteria were excluded, as were patients who underwent second-look endoscopy.

\section{Validity assessment and data abstraction}

Two reviewers independently identified and examined the relevant studies. A third independent reviewer resolved disagreements on specific studies. The quality of each study was assessed using modified Jadad criteria, in which an additional point was attributed for the description of allocation concealment, a priori sample size estimation, description and number of drop-outs, adequate description of the population selection and characteristics, for a total of 10 points from the initial five-point score (21). The Cochrane risk-of-bias tool (22) was also used.

\section{Assessment of heterogeneity}

Comparative qualitative analyses evaluated the homogeneity of study characteristics, such as patient populations, interventions and outcomes across studies, guiding possible sensitivity analyses.

Statistical heterogeneity was not sought because no inferential calculations were performed as part of the present analysis.

\section{Principal outcome, data synthesis and analysis}

Among all trials selected, only the arms satisfying the aforementioned criteria were considered.

Only descriptive data were generated from the present analysis, including patient characteristics and the main outcome of time to rebleeding.

Rebleeding at different time points - three days, seven days, 14 days, and 28 to 30 days - was examined. Weighted averages of rebleeding rates among all included studies were calculated for each time point; $95 \% \mathrm{CIs}$ were also reported. Additional data pertaining to different patient characteristics and previously recognized predictors of rebleeding were extracted and analyzed. The primary analysis included the assessment of study arms having administered only high-dose IV PPI ( $80 \mathrm{mg}$ bolus followed by $8 \mathrm{mg} / \mathrm{h}$ for three days); a planned sensitivity analysis examined studies including any dose of PPI $>40 \mathrm{mg}$ daily.

All statistical analyses were performed using SAS version 9.2 (SAS Institute Inc, USA).

\section{Study identification}

\section{RESULTS}

A total of 756 citations were initially identified; reasons for excluding studies are listed in Figure 1. Randomized controlled trials were excluded if epinephrine monotherapy was used in part of the patient population, such as in the study by Sung et al (15). Overall, eight arms from six full-text randomized controlled trials $(13,16,18,23-25)$ were included, yielding a total of 561 patients.

High-dose PPI ( $80 \mathrm{mg}$ IV bolus followed by $8 \mathrm{mg} / \mathrm{h}$ for $72 \mathrm{~h}$ ) was used in five study arms $(13,16,18,23,24)$, which comprised the primary analysis, yielding a total of 393 patients. The sensitivity analysis included any studies using PPI doses $>40 \mathrm{mg}$ (total of the above eight arms).

\section{Study characteristics}

Characteristics of the included studies are shown in Table 1 and summarized below.

Study populations: All patients exhibited bleeding gastric or duodenal ulcers demonstrating high-risk stigmata. Most studies used the Forrest classification and included Forrest type Ia to IIb ulcers (Ia: spurting; Ib: oozing; Ila: visible vessel; and IIb: adherent clot). One study classified ulcers according to stigmata of recent hemorrhage (16), either major or minor in type, as described in the study by Yang et al (10). The patients ranged in age from 55.3 to 67.5 years, with $58.5 \%$ to $89.5 \%$ being male. Active bleeding (Forrest Ia and Ib) occurred in $14.3 \%$ patients (18) to up to $53.3 \%$ (24). The presence of $\geq 1$ comorbidities ranged from $24.5 \%$ of patients (13) to $100 \%$ of patients in the study by Cheng et al (16). Hemodynamic instability or shock was recorded in four of six studies. It ranged from $13.3 \%$ (24) to up to $46.8 \%$ of patients in the study by Chiu et al (25). The proportion of patients categorized according to American Society of Anesthesiologists (ASA) scores varied (Table 1). The use of NSAIDs was recorded in almost all studies and ranged from $18 \%$ (13) to up to $57.9 \%$ (18). Mean ( \pm SD) ulcer size ranged from to $0.9 \pm 0.5 \mathrm{~cm}(25)$ to $1.4 \pm 1.2 \mathrm{~cm} \mathrm{(18)}$.

\section{Outcome definition}

The definition of rebleeding was similar among all studies. Rebleeding was defined clinically according to different parameters, including the presence of melena, hematemesis or fresh blood in the nasogastric 


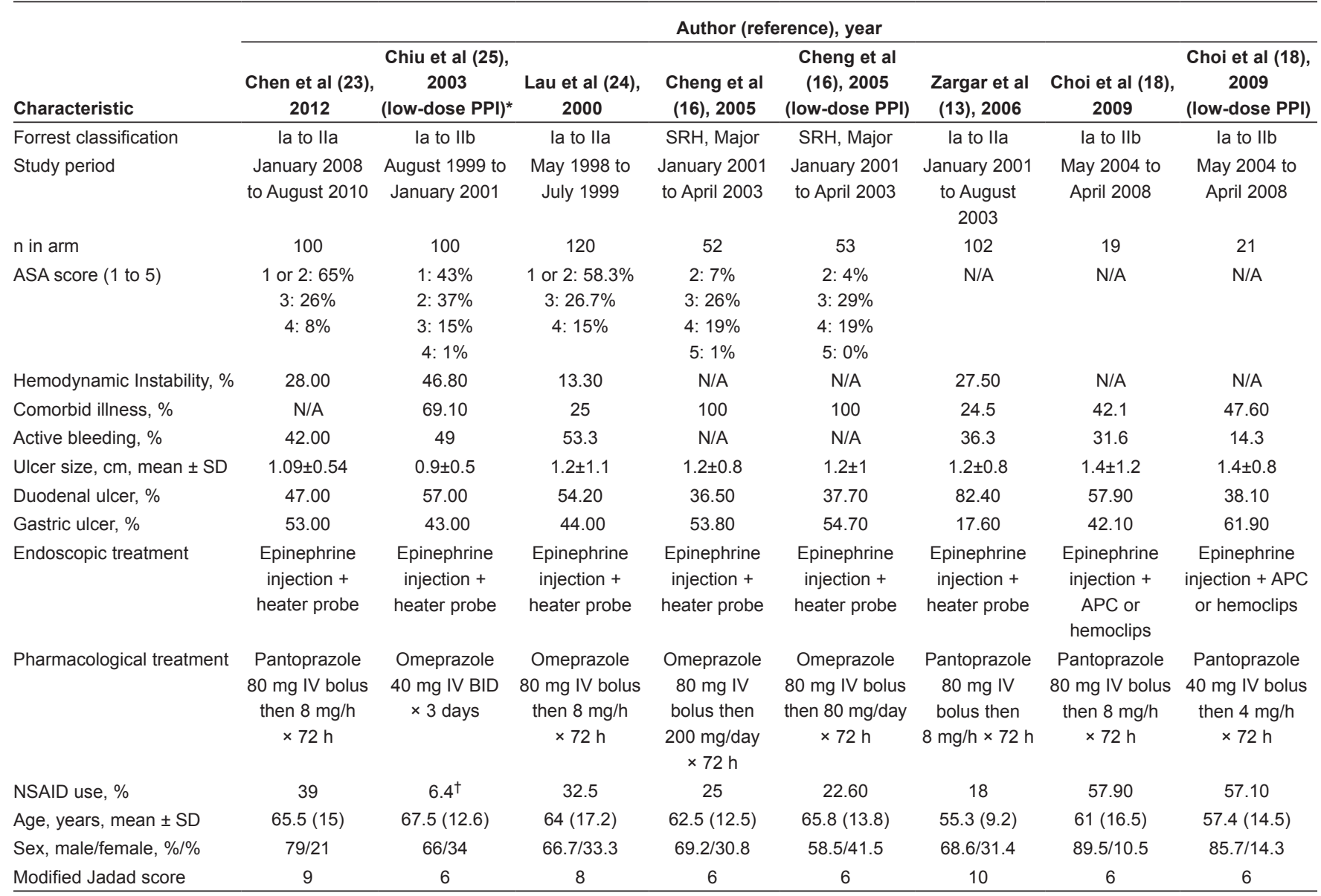

*No second-look endoscopy arm; ${ }^{+}$Only acetylsalicylic acid use reported. APC Argon plasma coagulation; ASA American Association of Anesthesiologists; BID Twice per day; IV Intravenous; N/A Not applicable; NSAID Nonsteroidal anti-inflammatory drug; PPI Proton pump inhibitor; SRH Stigmata of recent hemorrhage

tube, a change in vital signs (systolic blood pressure $<90 \mathrm{mmHg}$, heart rate $>100$ beats/min to 110 beats/min), drop in hemoglobin level, or sudden increase in transfusion requirements. Following clinical suspicion, rebleeding was then confirmed on endoscopy.

Performance of endoscopy and adjuvant therapy

Initial endoscopy was performed within $24 \mathrm{~h}$ of admission in all studies. In five of the six trials, endoscopic therapy involved epinephrine injection combined with thermocoagulation. In the study by Choi et al (18), epinephrine was used in addition to argon plasma coagulation and/or application of hemoclips.

Different PPI regimens were used among the studies with lower PPI dosing. One arm of the trial by Choi et al (18) used pantoprazole $40 \mathrm{mg}$ IV bolus followed by $4 \mathrm{mg} / \mathrm{h}$ for $72 \mathrm{~h} \mathrm{(18).} \mathrm{One} \mathrm{arm} \mathrm{of} \mathrm{the}$ study by Cheng et al (25) used omeprazole $80 \mathrm{mg}$ IV bolus followed by $80 \mathrm{mg}$ infusion per day for three days, and Chiu et al (16) used omeprazole $40 \mathrm{mg}$ IV twice daily for three days (25).

One-half of the trials used pantoprazole $(13,18,23)$, while the other one-half used omeprazole $(16,24,25)$.

Study quality

The quality of studies on the modified Jadad score varied from 6 to 10 points (Table 1 ), with a mean of $7.5 \pm 1.8$. The Cochrane risk-of-bias tool revealed overall low bias with a potential of bias for Choi et al (18) and Chen et al (23), in which the treatment allocation was not blinded (Figure 2).

Primary analysis: rebleeding in patients receiving high-dose PPIs Among the 393 patients receiving high-dose PPI, 45 rebled within the first 30 days, corresponding an overall rate of rebleeding of $11.5 \%$
(95\% CI 8.4\% to14.7\%). The rebleeding rate, broken down according to time following initial endoscopic hemostasis, is shown in Figure 3, with $55.6 \%$ rebleeding occurring within the first three days.

Sensitivity analysis: rebleeding in patients receiving PPI doses $>40 \mathrm{mg}$ once daily

When including all patients receiving PPI at a dose $>40 \mathrm{mg}$ once daily, 81 of 561 patients rebled at 30 days, corresponding to an overall rebleeding rate of $14.4 \%$ ( $95 \%$ CI $11.5 \%$ to $17.3 \%$ ). In this broader patient population, among those who rebled, $39.5 \%$ (95\% CI $28.9 \%$ to $50.15 \%)$ did so within three days.

Of note, in the study by Cheng at al (16), rebleeding rates showed a different trend. In the high-dose PPI arm, the overall rebleeding rate was $40.4 \%$ at 30 days. Among the patients who rebled, $38.1 \%$ did so by day $3,14.3 \%$ between days 4 and 7, 38.1\% between seven and 14 days, and $9.5 \%$ between day 14 and 28 to 30 . An exploratory a posteriori sensitivity analysis was subsequently performed. When excluding this study, the rebleeding rate among studies using high-dose PPI at day 3 was $70.8 \%, 25 \%$ between days 4 and 7 , and $4.2 \%$ between day 15 and 28 to 30 . Among studies using all PPI doses, rebleeding was $48.6 \%$, $48.6 \%$ and $2.7 \%$ at day 3 , between days 4 to 7 , and between day 14 and 28 to 30 , respectively.

\section{DISCUSSION}

The timing of rebleeding after endoscopic hemostasis in peptic ulcer bleeding remains unclear in the era of high-dose PPI and contemporary endoscopic therapy. Most of the current data regarding the timing of peptic ulcer rebleeding are obtained from studies using endoscopic hemostatic techniques and pharmacological therapies that are not 


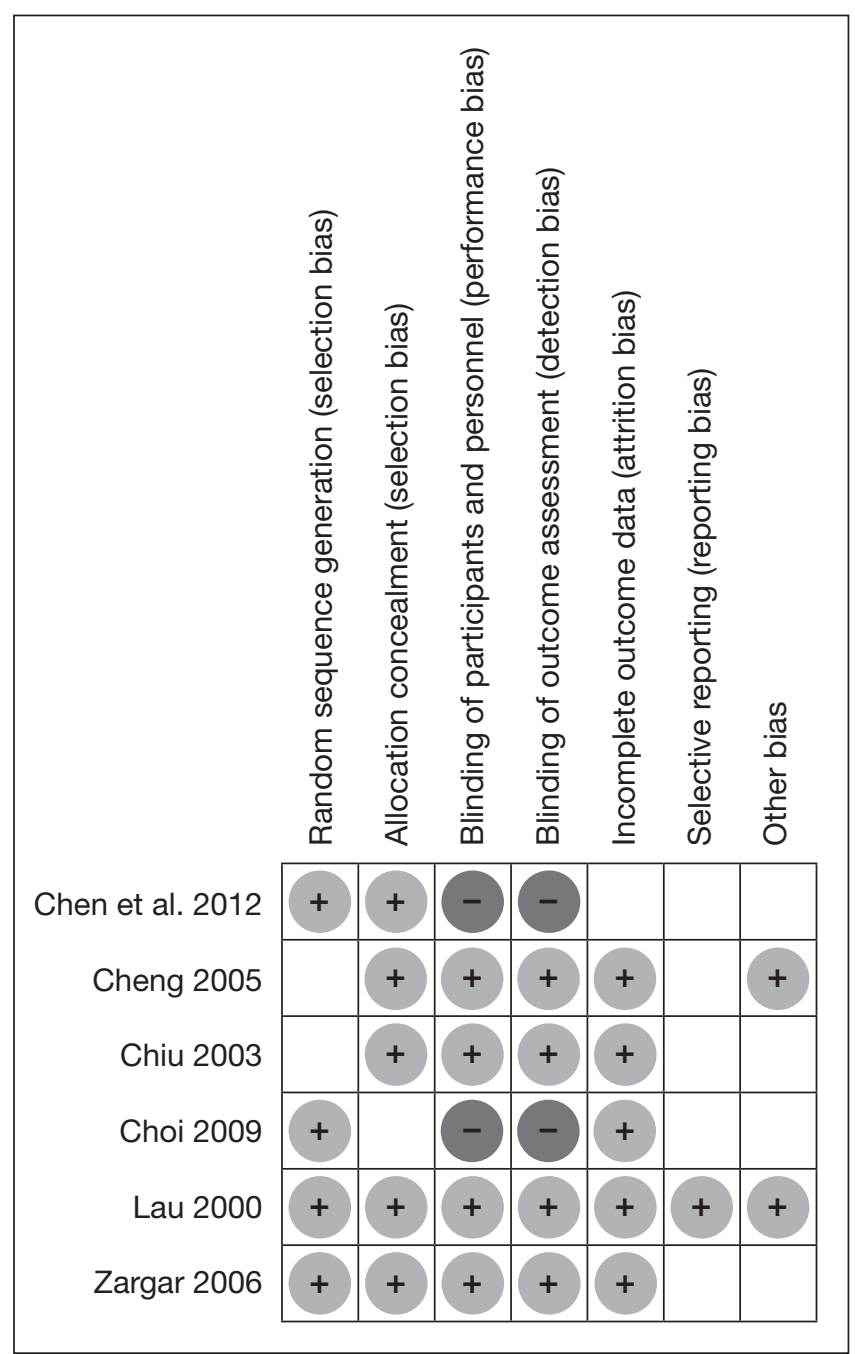

Figure 2) Risk of bias summary

consistent with current recommendations, with no PPI pharmacotherapy or low PPI doses, as well as epinephrine injection alone.

The finding that most rebleeding occurs within the first three days is also supported by several landmark studies in which endoscopic follow-up of ulcers showed healing with a clean base by day 3 to 4; however, most of these older studies excluded patients on NSAIDs or anticoagulants, and patients with any comorbidities, which is not reflective of a contemporary patient population $(7,9,11)$.

The aim of the present systematic review was, thus, to better examine the timing of peptic ulcer rebleeding in patients exhibiting highrisk stigmata who received recommended contemporary endoscopic and pharmacological therapies.

Our primary analysis evaluated studies using high-dose PPI infusion. Among patients who rebled, 55.6\% did so within three days. This is higher than what has been reported in the literature, with rebleeding rates of up to $95 \%$ in the first three days $(7,8,11,26)$.

When analyzing rebleeding rates among the included studies, the study by Cheng et al (16) appears to stand out, demonstrating different trends in rebleeding with an overall high rate of rebleeding of $40.4 \%$. Furthermore, among patients who rebled, only $38.1 \%$ did so by day 3 . When excluding this outlier study, $70.8 \%$ of patients rebled by day 3 , which is more consistent with rates reported in the literature.

We closely examined the study by Cheng et al (16) to better understand the difference in rebleeding trends reported in this trial. In this study, patients had to have at least one comorbidity to be included. In other words, $100 \%$ of their patients had at least one other coexisting illness, which is higher than all other included studies that enrolled

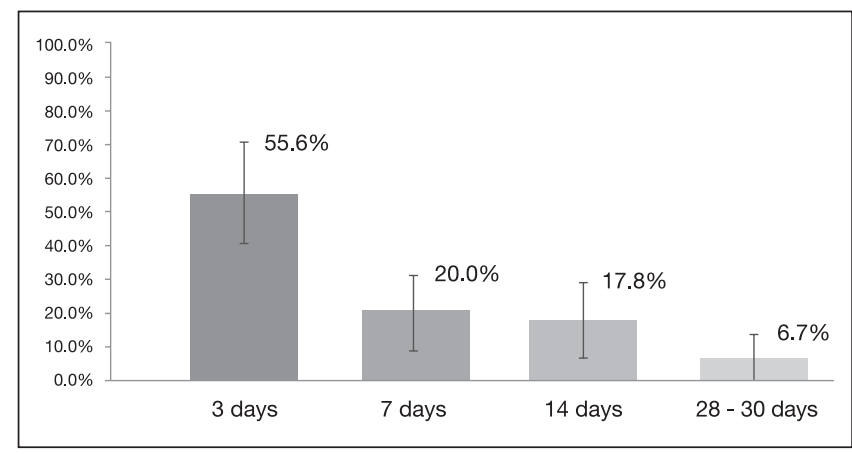

Figure 3) Rebleeding rates at different time points in patients receiving highdose proton pump inhibitors (95\% CIs represented by vertical lines)

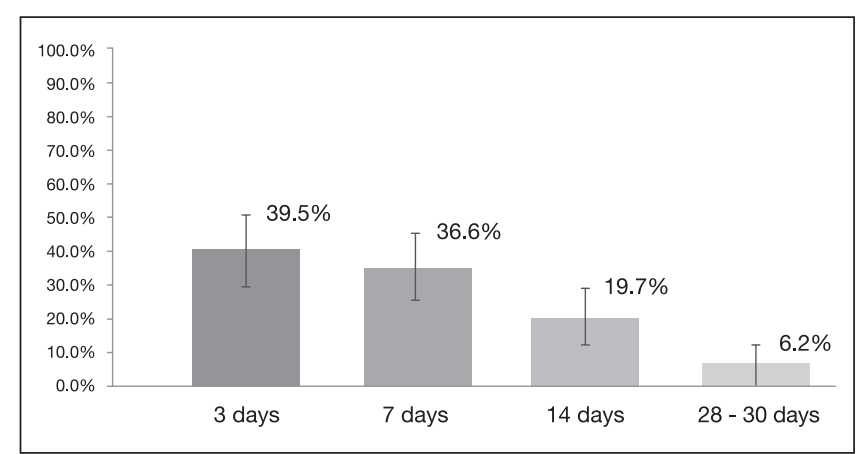

Figure 4) Rebleeding rates at different time points in patients receiving lower doses of proton pump inhibitors

patient populations without comorbidities in proportions of up to $75 \%$. Furthermore, in the study by Cheng et al (16), up to $48.1 \%$ had $\geq 2$ comorbidities. Although they did not report the rates of hemodynamic instability or shock, $48 \%$ of their patients had an ASA score $\geq 3$, demonstrating a sicker patient profile than all other included studies. When including all studies using PPI doses $>40 \mathrm{mg}$ daily, only $39.5 \%$ of patients who rebled did so within the first $72 \mathrm{~h}$, with the remainder rebleeding mostly between days 4 and 7 . When excluding the 'outlier' study by Cheng et al (16), the trend toward increased delayed rebleeding persisted, with $51.3 \%$ of patients rebleeding after the three-day period, including $48.6 \%$ bleeding by day 7 .

To determine why most patients rebled after the three-day period in the lower-dose PPI analysis, we performed an explorative qualitative review, comparing patient characteristics among the included studies. Unfortunately, no patient-level data were available. However, on qualitatively reviewing the data, several factors appeared to be possibly associated with delayed rebleeding.

First, higher rates of delayed rebleeding were found when including studies using PPIs at lower doses, which suggests that PPI dosing may not only affect rebleeding rates, as it is already established, but may also impact the timing of rebleeding. Interestingly, a recently published RCT demonstrated decreased rates of delayed peptic ulcer rebleeding among high-risk patients receiving a prolonged 11-day course of twice daily PPI dosing (27).

In addition to lower PPI doses, the presence of coexisting illness may also impact the timing of rebleeding. Among the included studies, trials enrolling patients with higher rates of comorbidities appear to demonstrate delayed rebleeding. Cheng et al (16), as described above, included all patients with at least one comorbidity and had higher rates of delayed rebleeding. Another included study, by Chiu et al (25), had patients with high rates of comorbidities (up to 69.1\%). Rebleeding was also delayed in this trial, with most patients rebleeding between days 4 and 7. Choi et al (18) included up to $47.6 \%$ of patients with comorbidities (up to $42.1 \%$ in the high-dose PPI arm). In these arms, the only patient who rebled did so on day 6 - after the $72 \mathrm{~h}$ period. 
The presence of comorbidities as a factor leading to increased rebleeding and mortality has been demonstrated in the literature $(3,28$ 30); however, its association with delayed rebleeding had not yet been shown. In the present systematic review, no data could be extracted regarding the different types of comorbidities because most studies reported these without further categorization according to system. Cheng et al (16) identified the presence of hypoalbuminemia (albumin $<30 \mathrm{~g} / \mathrm{L}$ ) as well as having $\geq 2$ comorbidities as associated with a higher trend of rebleeding between days 4 and 14 in univariable analysis. Endstage renal disease (ESRD) was also associated, but with more delayed rebleeding. Only ESRD was significantly increased among patients who rebled between days 15 to 28 in multivariable analysis.

Patients with renal disease and ESRD are not only at increased risk for upper gastrointestinal bleeding (31), but also appear to have worse outcomes related to peptic ulcer bleeding. Patients with ESRD exhibit higher rates of rebleeding (up to $40.6 \%$ in study by Cheung et al [32]), as well as increased delayed rebleeding (beyond seven days) $(16,33)$. ESRD has also been associated with increased long-term peptic ulcer rebleeding (34).

Patients with ESRD may be at higher risk for peptic ulcer rebleeding due to multiple factors, mainly bleeding diathesis. This is believed to be due to platelet dysfunction in the context of uremia, as well as impaired platelet-vessel wall interaction (35). Dialysis may also contribute to increased bleeding through exposure to heparin as well as through continuous platelet activation, due to interaction of blood with artificial surfaces $(35,36)$.

In addition, ESRD is associated with lower albumin levels and poor nutrition, thereby possibly leading to slower ulcer healing and, perhaps, a greater risk of rebleeding (33). The impact of gastric acid secretion remains unclear because it has been shown to be increased in some studies, and decreased or normal in others $(33,37)$.

Hemodynamic instability and higher ASA scores have also been shown in the literature to be associated with higher rates of rebleeding and overall poorer prognosis $(3,38-40)$.

Interestingly, in the present analysis, studies demonstrating higher rates of delayed rebleeding had higher rates of unstable patients as well as a higher number of patients with an ASA score $>3(16,25)$. However, hemodynamic instability and ASA score were not systematically recorded in all included studies.

\section{CONCLUSION}

The results of the present systematic review appear to demonstrate higher rates of delayed rebleeding when including studies using modern-day endoscopic hemostatic technique as well as intravenous PPI. A qualitative review of patient characteristics from studies exhibiting delayed rebleeding suggests that possible associations may include increased patient comorbidity and use of lower doses of PPI following endoscopic hemostasis, as well as increased hemodynamic instability and higher ASA scores. However, such associations are limited by lack of patient-level data and the limited number of studies available. In addition, there existed significant clinical heterogeneity. Timing of rebleeding among patients receiving modern-day therapy and determinants of delayed rebleeding should be further explored in future research, as this could greatly impact on the outcomes of patients with peptic ulcer bleeding (and perhaps other etiologies) by adapting care to patients at increased risk for delayed rebleeding, through the use of second-look endoscopy, or better adapted follow-up oral PPI dosing.

DISCLOSURES: Dr Alan Barkun is a consultant for Olympus and Takeda Canada; is a speaker for Takeda Canada and AstraZeneca; is on the advisory board for Pendopharm Canada; and received research funding from Boston Scientific and Cook. Dr Sara El Ouali, Ms Myriam Martel and Dr Davide Maggio have no financial disclosures or conflicts of interest to declare.
FUNDING: None.

AUTHOR'S CONTRIBUTIONS: Conception and design: Sara E Ouali, Alan N Barkun, Myriam Martel and Davide Maggio; analysis and interpretation of data: Sara El Ouali, Alan N Barkun, Myriam Martel and Davide Maggio. Drafting of the manuscript: Sara El Ouali, Alan N Barkun, Myriam Martel and Davide Maggio. Critical revision of the article for important intellectual content: Sara El Ouali, Alan N Barkun, Myriam Martel and Davide Maggio. Final approval of the article: Sara El Ouali, Alan N Barkun, Myriam Martel and Davide Maggio.

\section{REFERENCES}

1. Garcia-Iglesias P, Villoria A, Suarez D, et al. Meta-analysis: Predictors of rebleeding after endoscopic treatment for bleeding peptic ulcer. Aliment Pharmacol Ther 2011;34:888-900.

2. Gralnek IM, Barkun AN, Bardou M. Management of acute bleeding from a peptic ulcer. N Engl J Med 2008;359:928-37.

3. Barkun AN, Bardou M, Kuipers EJ, et al. International consensus recommendations on the management of patients with nonvariceal upper gastrointestinal bleeding. Ann Intern Med 2010;152:101-13.

4. Barkun A, Sabbah S, Enns R, et al. The Canadian Registry on Nonvariceal Upper Gastrointestinal Bleeding and Endoscopy (RUGBE): Endoscopic hemostasis and proton pump inhibition are associated with improved outcomes in a real-life setting. Am J Gastroenterol 2004;99:1238-46.

5. Peura DA, Lanza FL, Gostout CJ, Foutch PG. The American College of Gastroenterology Bleeding Registry: Preliminary findings. Am J Gastroenterol 1997;92:924-8.

6. Vreeburg EM, Snel P, de Bruijne JW, Bartelsman JF, Rauws EA, Tytgat GN. Acute upper gastrointestinal bleeding in the Amsterdam area: Incidence, diagnosis, and clinical outcome. Am J Gastroenterol 1997;92:236-43.

7. Hsu PI, Lai KH, Lin XZ, et al. When to discharge patients with bleeding peptic ulcers: A prospective study of residual risk of rebleeding. Gastrointest Endosc 1996;44:382-7.

8. Hsu PI, Lin XZ, Chan SH, et al. Bleeding peptic ulcer - risk factors for rebleeding and sequential changes in endoscopic findings. Gut 1994:35:746-9.

9. Lau JY, Chung SC, Leung JW, Lo KK, Yung MY, Li AK. The evolution of stigmata of hemorrhage in bleeding peptic ulcers: A sequential endoscopic study. Endoscopy 1998;30:513-8.

10. Yang CC, Shin JS, Lin XZ, Hsu PI, Chen KW, Lin CY. The natural history (fading time) of stigmata of recent hemorrhage in peptic ulcer disease. Gastrointest Endosc 1994;40:562-6.

11. Lin HJ, Perng CL, Lee FY, Lee CH, Lee SD. Clinical courses and predictors for rebleeding in patients with peptic ulcers and non-bleeding visible vessels: A prospective study. Gut 1994:35:1389-93.

12. Laine L, Jensen DM. Management of patients with ulcer bleeding. Am J Gastroenterol 2012;107:345-60.

13. Zargar SA, Javid G, Khan BA, et al. Pantoprazole infusion as adjuvant therapy to endoscopic treatment in patients with peptic ulcer bleeding: Prospective randomized controlled trial. J Gastroenterol Hepatol 2006;21:716-21.

14. Jensen DM, Pace SC, Soffer E, Comer GM, Study G. Continuous infusion of pantoprazole versus ranitidine for prevention of ulcer rebleeding: A U.S. multicenter randomized, double-blind study. Am J Gastroenterol 2006;101:1991-9.

15. Sung JJ, Barkun A, Kuipers EJ, et al. Intravenous esomeprazole for prevention of recurrent peptic ulcer bleeding: A randomized trial. Ann Intern Med 2009;150:455-64

16. Cheng HC, Kao AW, Chuang CH, Sheu BS. The efficacy of high- and low-dose intravenous omeprazole in preventing rebleeding for patients with bleeding peptic ulcers and comorbid illnesses. Dig Dis Sci 2005;50:1194-201.

17. Chiu PW, Lam CY, Lee SW, et al. Effect of scheduled second therapeutic endoscopy on peptic ulcer rebleeding: A prospective randomised trial. Gut 2003;52:1403-7.

18. Choi KD, Kim N, Jang IJ, et al. Optimal dose of intravenous pantoprazole in patients with peptic ulcer bleeding requiring endoscopic hemostasis in Korea. J Gastroenterol Hepatol 2009;24:1617-24. 
19. Barkun AN, Bhat M, Armstrong D, et al. Effectiveness of disseminating consensus management recommendations for ulcer bleeding: A cluster randomized trial. CMAJ 2013 19;185:E156-66.

20. Hayes SM, Murray S, Dupuis M, Dawes M, Hawes IA, Barkun AN. Barriers to the implementation of practice guidelines in managing patients with nonvariceal upper gastrointestinal bleeding: A qualitative approach. Can J Gastroenterol 2010;24:289-96.

21. Jadad AR, Moore RA, Carroll D, et al. Assessing the quality of reports of randomized clinical trials: Is blinding necessary? Control Clin Trials 1996;17:1-12.

22. Higgins JP, Green S, Cochrane Collaboration. Cochrane handbook for systematic reviews of interventions. Chichester: Hoboken: Wiley-Blackwell, 2008.

23. Chen CC, Lee JY, Fang YJ, et al. Randomised clinical trial: High-dose vs. standard-dose proton pump inhibitors for the prevention of recurrent haemorrhage after combined endoscopic haemostasis of bleeding peptic ulcers. Aliment Pharmacol Ther 2012;35:894-903.

24. Lau JY, Sung JJ, Lee KK, et al. Effect of intravenous omeprazole on recurrent bleeding after endoscopic treatment of bleeding peptic ulcers. N Engl J Med 2000;343:310-6.

25. Chiu PW, Lam CY, Lee SW, et al. Effect of scheduled second therapeutic endoscopy on peptic ulcer rebleeding: A prospective randomised trial. Gut 2003;52:1403-7.

26. Laine L, Jensen DM. Management of patients with ulcer bleeding. Am J Gastroenterol 2012;107:345-60.

27. Cheng HC, Wu CT, Chang WL, Cheng WC, Chen WY, Sheu BS. Double oral esomeprazole after a 3-day intravenous esomeprazole infusion reduces recurrent peptic ulcer bleeding in high-risk patients: A randomised controlled study. Gut March 21, 2014 (Epub ahead of print).

28. Cappell MS, Nadler SC. Increased mortality of acute upper gastrointestinal bleeding in patients with chronic obstructive pulmonary disease. A case controlled, multiyear study of 53 consecutive patients. Dig Dis Sci 1995;40:256-62.

29. Lin HJ, Wang K, Perng CL, Lee FY, Lee CH, Lee SD. Natural history of bleeding peptic ulcers with a tightly adherent blood clot: A prospective observation. Gastrointest Endosc 1996;43:470-3.
30. Cheng HC, Chuang SA, Kao YH, Kao AW, Chuang CH, Sheu BS. Increased risk of rebleeding of peptic ulcer bleeding in patients with comorbid illness receiving omeprazole infusion.

Hepatogastroenterology 2003;50:2270-3.

31. Wasse H, Gillen DL, Ball AM, et al. Risk factors for upper gastrointestinal bleeding among end-stage renal disease patients. Kidney Int 2003;64:1455-61.

32. Cheung J, Yu A, LaBossiere J, Zhu Q, Fedorak RN. Peptic ulcer bleeding outcomes adversely affected by end-stage renal disease. Gastrointest Endosc 2010;71:44-9.

33. Tseng GY, Fang CT, Lin HJ, et al. Efficacy of an intravenous proton pump inhibitor after endoscopic therapy with epinephrine injection for peptic ulcer bleeding in patients with uraemia: A case-control study. Aliment Pharmacol Ther 2009;30:406-13.

34. Wu CY, Wu MS, Kuo KN, Wang CB, Chen YJ, Lin JT. Long-term peptic ulcer rebleeding risk estimation in patients undergoing haemodialysis: A 10-year nationwide cohort study. Gut 2011;60:1038-42.

35. Boccardo P, Remuzzi G, Galbusera M. Platelet dysfunction in renal failure. Semin Thromb Hemost 2004;30:579-89.

36. Kaw D, Malhotra D. Platelet dysfunction and end-stage renal disease. Semin Dial 2006;19:317-22.

37. Ponticelli C, Passerini P. Gastrointestinal complications in renal transplant recipients. Transpl Int 2005;18:643-50.

38. Garcia-Iglesias P, Villoria A, Suarez D, et al. Meta-analysis: Predictors of rebleeding after endoscopic treatment for bleeding peptic ulcer. Aliment Pharmacol Ther 2011;34:888-900.

39. Chiu PW, Joeng HK, Choi CL, Kwong KH, Ng EK, Lam SH. Predictors of peptic ulcer rebleeding after scheduled second endoscopy: Clinical or endoscopic factors? Endoscopy 2006;38:726-9.

40. Corley DA, Stefan AM, Wolf M, Cook EF, Lee TH. Early indicators of prognosis in upper gastrointestinal hemorrhage. Am J Gastroenterol 1998;93:336-40. 


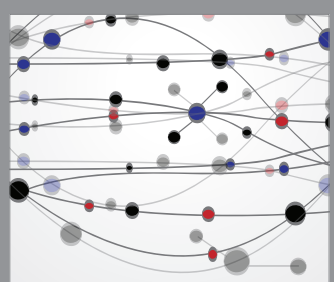

The Scientific World Journal
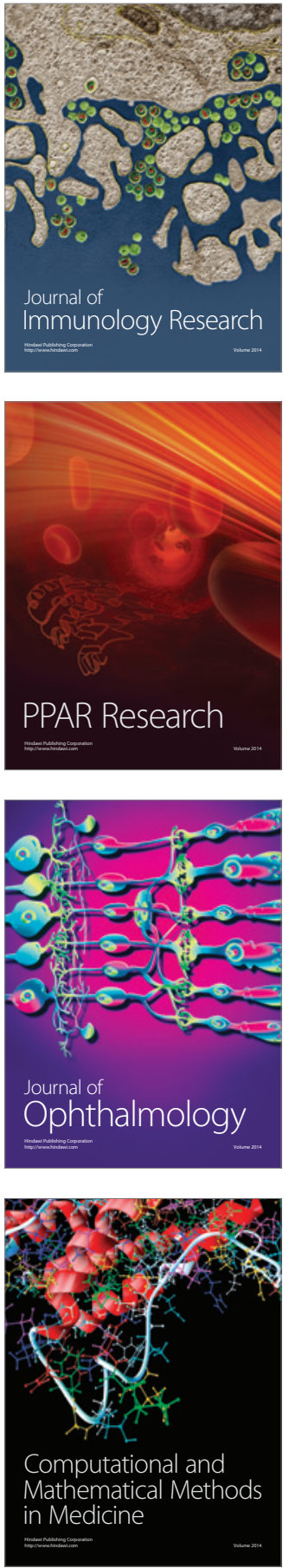

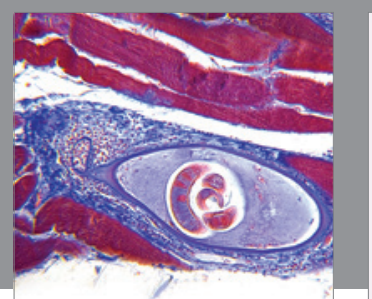

Gastroenterology Research and Practice

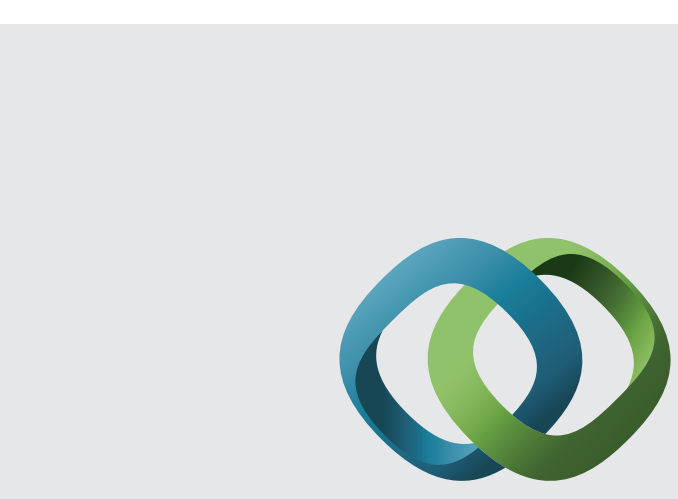

\section{Hindawi}

Submit your manuscripts at

http://www.hindawi.com
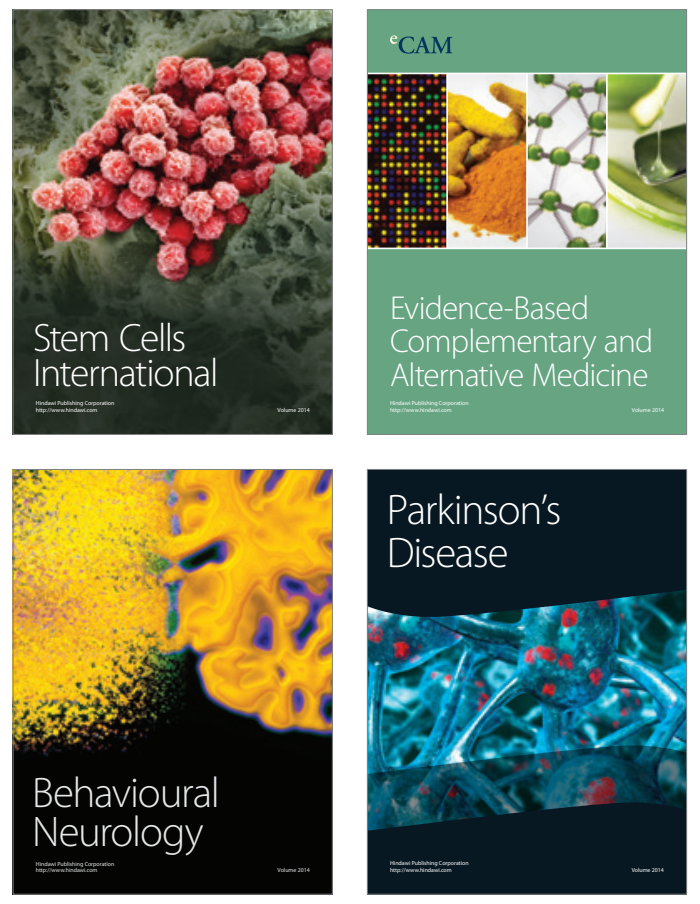
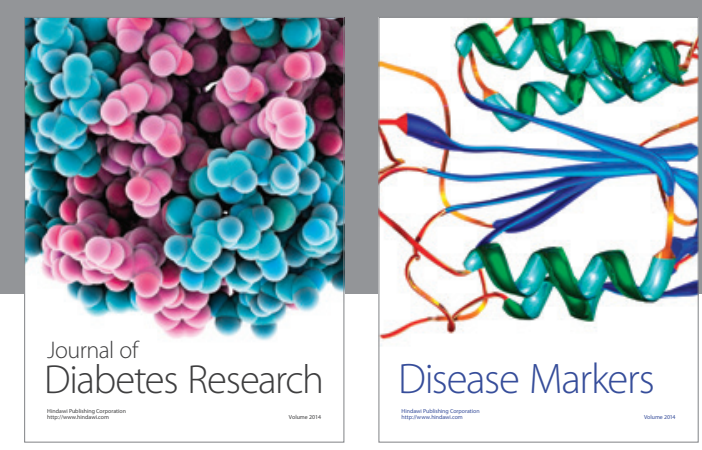

Disease Markers
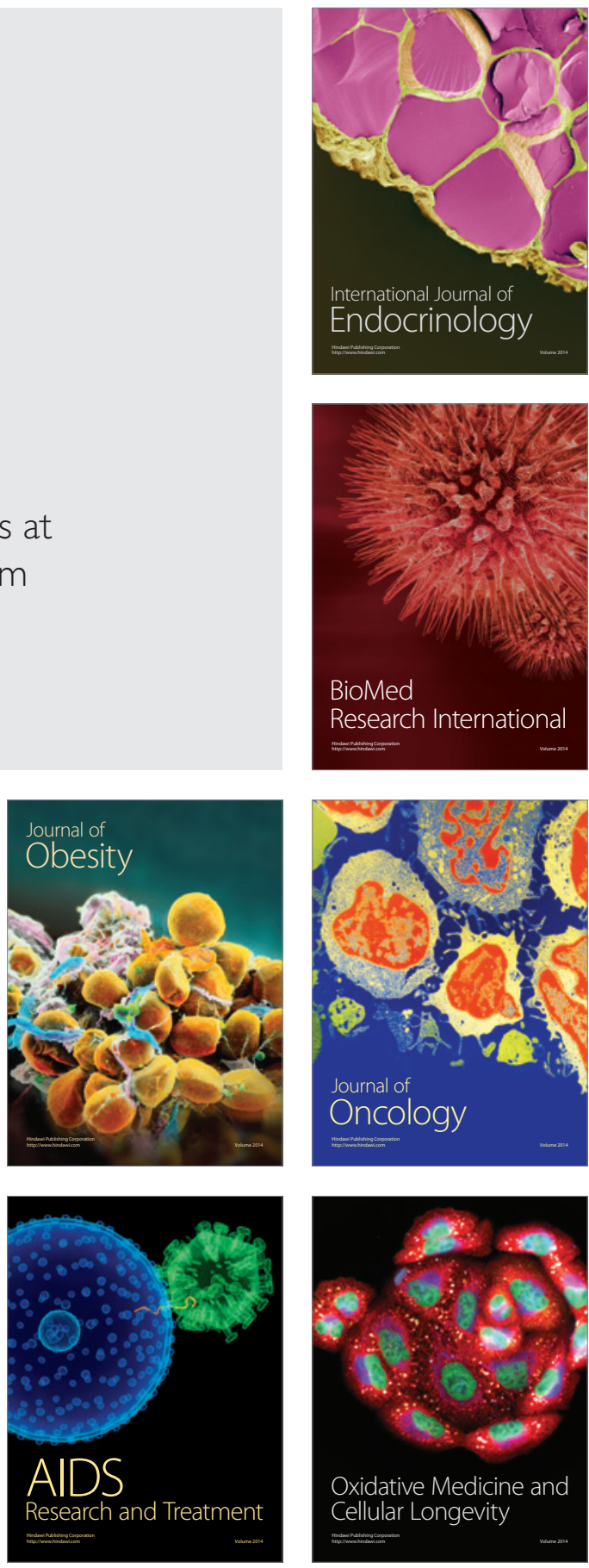